\title{
Produksi kacang tanah (Arachis hypogaea L. Var. Takar) pada perbedaan waktu inokulasi Rhizobium sp. dan pemberian berbagai mulsa organik di lahan salin
}

\author{
(Yield of groundnut (Arachis hypogaea L. Var. Takar) at the difference time of Rhizobium \\ $s p$. Inoculation and various organic mulching materials on saline soil) \\ H. F. Asyari, , E. Fuskhah, dan E. D. Purbajanti \\ Agricultural Department, Faculty of Animal and Agricultural Sciences, Diponegoro University \\ Tembalang, Semarang 50275 - Indonesia \\ CorrespondingE-mail: eny_fuskhah@yahoo.com
}

\begin{abstract}
Aim of this research was to examine the effect of inoculation's time and various organic mulching materials on yield of groundnut (Arachis hypogaea L. Var. Takar) on soil with $6,4 \mathrm{dS} / \mathrm{m}$ salinity level. The research was conducted at Desa Bulakbaru, Kecamatan Kedung, Kabupaten Jepara. The research used Randomized Complete Block Design Factorials 4 × 3 and 3 groups. The first factor was timing of inoculation Rhizobium sp. in T0: without inoculation, T1: inoculation during planting, T2: 7 DAP inoculation, T3: 14 DAP inoculation. The second factor was various organic mulching materials in R0: without mulching, R1: paddy straw mulching, R2: paddy husk mulching. The observed parameters were plant height, leaves total, pods/plot total, pods/plot weight, seeds/plots total, root nodules/plots total and 100 seeds weight. The result showed that R1 have significant effect on average plant height in the amount of $62,1 \mathrm{~cm}$ and $\mathrm{T} 1$ have significant effect on root nodules in the amount of 1,86/plant. There was no effect and interraction on the other parameters. The conclusion was paddy straw mulching was able to improve the plant height and inoculation during planting was able to improve amount of root nodules on land with $6,4 \mathrm{dS} / \mathrm{m}$ salinity level.
\end{abstract}

Keywords : groundnut, salinity, rhizobium sp, mulching.

\begin{abstract}
ABSTRAK
Tujuan penelitian adalah mengkaji waktu inokulasi terbaik dan pemberian berbagai jenis mulsa organik terhadap produksi kacang tanah (Arachis hypogaea L. Var. Takar) pada lahan salin dengan tingkat salinitas 6,4 dS/m. Penelitian kali ini dilaksanakan di Desa Bulakbaru, Kecamatan Kedung, Kabupaten Jepara. Rancangan yang digunakan adalah RAK Faktorial 4 x 3 dengan 3 kelompok. Faktor pertama adalah perbedaan waktu inokulasi Rhizobium $s p$. yaitu T0: tanpa inokulasi, T1: inokulasi saat tanam, T2: inokulasi 7 HST, dan inokulasi 14 HST. Faktor kedua adalah berbagai jenis mulsa organik yaitu R0: tanpa mulsa organik, R1: mulsa organik jerami padi, dan R2: mulsa organik sekam padi. Parameter yang diamati adalah tinggi tanaman, jumlah daun, jumlah polong per petak, bobot polong per petak, jumlah biji per petak, jumlah bintil akar dan bobot 100 biji. Hasil penelitian menunjukkan bahwa R1 menunjukkan peningkatan rerata tinggi tanaman sebesar $62,1 \mathrm{~cm}$ dan T1 menunjukkan rerata jumlah bintil akar tertinggi sebesar 1,86/tanaman. Tidak ada pengaruh dan interaksi pad parameter lain. Kesimpulan yang diperoleh adalah mulsa organik jerami mampu meningkatkan tinggi tanaman dan waktu inokulasi saat tanam dapat meningkatkan jumlah bintil akar di lahan dengan tingkat salinitas 6,4 $\mathrm{dS} / \mathrm{m}$.
\end{abstract}

Kata kunci : kacang tanah, salinitas, rhizobium sp, mulsa organik. 


\section{PENDAHULUAN}

Tahun 2013 dan 2014, produksi kacang tanah mencapai 120.000 ton, sementara pada tahun 2015, produksi kacang tanah hanya mampu sebesar 109.204 ton (BPS, 2016). Ambang batas salinitas maksimal kacang tanah untuk menghasilkan polong dan biji adalah 1,60 - 1,84 dS/m (Taufiq et al., 2015). Umur panen dari kacang tanah varietas Takar adalah 85 - 90 HST (Kasno dan Harnowo, 2014). Kacang tanah memiliki dua tipe tumbuh berdasarkan pertumbuhan batang, yaitu tipe tegak dan menjalar dengan masa panen yang berbeda. Tanaman kacang tanah memiliki habitus terna dengan tinggi tanaman yang hanya mencapai $30-50 \mathrm{~cm}$ dan tipe daun majemuk dengan 4 anak daun (Gresinta, 2015). Polong dan buah kacang tanah terbentuk ketika ginofor menembus tanah. Tanah yang gembur akan memudahkan ginofor untuk menembus tanah (Sembiring et al., 2014).

Mulsa merupakan bahan organik maupun anorganik yang dihamparkan diatas permukaan tanah budidaya dengan tujuan menjaga sifat fisik tanah. Penggunaan mulsa organik dapat menurunkan suhu tanah serta meningkatkan kelembaban tanah dibandingkan dengan tidak menggunakan mulsa organik pada kedalaman tanah $5 \mathrm{~cm}$ (Handani, 2009). Mulsa organik dapat berfungsi untuk menambah bahan organik tanah serta mengendalikan iklim mikro pada lahan budidaya, sehingga sesuai untuk tempat berkembang biak dari bakteri Rhizobium sp. (Ni'am dan Bintari, 2017). Penelitian sebelumnya menjelaskan bahwa mulsa jerami padi dapat berfungsi sebagai amelioran, sehingga dapat menurunkan $\mathrm{Na}+, \mathrm{K}+, \mathrm{Ca} 2+, \mathrm{Mg} 2+$, dan $\mathrm{Cl}-$ secara signnfikan (Purwaningrahayu dan Kuntyastuti, 2016). Mulsa jerami padi dan sekam padi memiliki unsur hara $\mathrm{P}$ berturut-turut sebesar $0,15 \%$ dan 0,08\% (Sughening et al., 2012). Mulsa organik sekam padi juga dapat mempengaruhi pertumbuhan tanaman. Berdasarkan penelitian sebelumnya, tinggi tanaman legum pada umur 12 , 24, dan 60 HST meningkat secara signifikan ketika diberi mulsa organik sekam padi (Prasetyo et al., 2014).

Lahan salin memiliki kendala bagi budidaya tanaman pangan. Hal ini dikarenakan tanah salin dapat menghambat pertumbuhan tanaman dengan cara mengganggu penyerapan unsur hara pada tanaman karena adanya larutan garam berlebih pada tanah (Aminah et al., 2013). Salinitas tanah dengan nilai kurang dari $2 \mathrm{dS} / \mathrm{m}$ dikategorikan rendah, 2-4 dS/m dikategorikan sedang, 4-8 dS/m dikategorikan tinggi dan lebih dari $8 \mathrm{dS} / \mathrm{m}$ dikategorikan tinggi (Marwanto et al., 2009). Berdasarkan penelitian sebelumnya, tanaman kacang tanah pada salinitas 5,43 - 6,45 berpengaruh nyata terhadap penurunan pembentukan polong (Taufiq et al. 2015). Kacang tanah yang ditanam pada tingkat salinitas $2 \mathrm{dS} / \mathrm{m}$ - $10 \mathrm{ds} / \mathrm{m}$ mengalami penurunan hasil sebanyak 100\% (Mungala et al., 2009). Penelitian lain menjelaskan bahwa EC sebesar 20,45 mmhos/cm menghambat pertumbuhan bakteri Rhizobium $s p$. secara signifikan (Fuskhah et al., 2014)

Tujuan dari penelitian adalah mengkaji waktu inokulasi bakteri Rhizobium $s p$. terbaik guna meningkatkan pertumbuhan dan produksi kacang tanah (Arachis hypogaea L. Var. Takar) pada lahan salin, mengetahui jenis mulsa organik terbaik untuk meningkatkan pertumbuhan dan produksi kacang tanah (Arachis hypogaea L. Var. Takar) pada lahan salin, serta mengetahui interaksi antara waktu inokulasi bakteri Rhizobium $s p$. dan jenis mulsa organik terbaik untuk meningkatkan pertumbuhan dan produksi kacang tanah (Arachis hypogaea L. Var. Takar) pada lahan salin.

Tabel 1. Hasil Analisis Salinitas Tanah Awal

\begin{tabular}{lc}
\hline Parameter Tanah & Kadar Salinitas \\
\hline TDS & $3,22 \mathrm{ppm}$ \\
$\mathrm{EC}$ & $6,4 \mathrm{dS} / \mathrm{m}$ \\
$\mathrm{NaCl}$ & $12,7 \%$ \\
\hline
\end{tabular}


Tabel 2. Rerata Tinggi Tanaman Kacang Tanah (Arachis hypogaea L. Var. Takar) pada Berbagai Jenis Mulsa Organik dan Perbedaan Waktu Inokulasi Bakteri Rhizobium sp.

\begin{tabular}{|c|c|c|c|c|c|}
\hline \multirow[b]{2}{*}{ Mulsa Organik } & \multicolumn{4}{|c|}{ Perbedaan Waktu Inokulasi Rhizobium sp. } & \multirow[b]{2}{*}{ Rerata } \\
\hline & $\begin{array}{c}\text { Tanpa } \\
\text { Inokulasi }\end{array}$ & $\begin{array}{c}\text { Inokulasi } \\
\text { Saat Tanam }\end{array}$ & $\begin{array}{c}\text { Inokulasi } 7 \\
\text { HST }\end{array}$ & $\begin{array}{c}\text { Inokulasi } \\
14 \mathrm{HST}\end{array}$ & \\
\hline & \multicolumn{5}{|c|}{----------------------------- $(\mathbf{c m})$----------------------------- } \\
\hline Tanpa Mulsa Organik & 45,3 & 43,8 & 57,2 & 44,4 & $47,7^{\mathrm{b}}$ \\
\hline $\begin{array}{c}\text { Mulsa Organik Jerami } \\
\text { Padi }\end{array}$ & 57,1 & 61,6 & 69,4 & 60,4 & $62,1^{\mathrm{a}}$ \\
\hline $\begin{array}{c}\text { Mulsa Organik Sekam } \\
\text { Padi }\end{array}$ & 44 & 53,9 & 45,9 & 56,5 & $50,1^{\mathrm{b}}$ \\
\hline Rerata & 48,8 & 53,1 & 57,5 & 53,7 & \\
\hline
\end{tabular}

*superskrip yang berbeda pada kolom rerata menunjukkan perbedaan yang nyata $(\mathrm{p}<0,05)$.

\section{MATERI DAN METODE}

Penelitian dilaksanakan pada 24 Juli 2018 6 Januari 2019 di Desa Bulakbaru, Kecamatan Kedung, Kabupaten Jepara serta laboratorium Tropical Marine and Biotechnology, Departemen Kelautan, Fakultas Perikanan dan Ilmu Kelautan, Universitas Diponegoro, Semarang dan laboratorium Ekologi dan Produksi Tanaman, Departemen Pertanian, Fakultas Peternakan dan Pertanian, Universitas Diponegoro, Semarang.

\section{Materi}

Bahan-bahan yang digunakan dalam penelitian ini adalah batang bawah durian dengan vairan umur 6, 9, dan 12 bulan, entres durian varietas bawor, IAA (Indhole Acetic Acid), aquades, alkohol $70 \%$. Alat yang digunakan antara lain erlenmeyer, gelas ukur, corong, timbangan analitik, spatula, cotton bud, selang, pisau okulasi, gunting dahan, plastik okulasi, plastik label, penggaris, kamera, dan alat tulis.

\section{Metode Penelitian}

Penelitian dilakukan Metode yang digunakan adalah Rancangan Acak Kelompok (RAK) faktorial 4 x 3 dengan 3 kelompok. Faktor pertama adalah perbedaan waktu inokulasi Rhizobium $s p$. dengan 4 perlakuan, yaitu T0 : tanpa inokulasi
Rhizobium sp. tahan salin, $\mathrm{T} 1$ : inokulasi Rhizobium sp. tahan salin pada saat tanam, T2 : inokulasi Rhizobium $s p$. tahan salin pada umur 7 HST, dan T3 : inokulasi Rhizobium sp. tahan salin pada umur 14 HST. Faktor yang kedua digunakan adalah berbagai jenis mulsa organik dengan 3 perlakuan, yaitu : R0 : tanpa pemberian mulsa organik, R1 : pemberian mulsa jerami padi, R2 : pemberian mulsa sekam padi. Sehingga terdapat 36 unit percobaan.

\section{Pelaksanaan}

Penelitian dilakukan melalui 2 tahap yaitu tahap persiapan dan pelaksanaan. Tahap persiapan sebelum penanaman disiapkan koloni bakteri Rhizobium sp. terseleksi, benih kacang tanah varietas takar, pupuk urea, pupuk SP-36, pupuk $\mathrm{KCl}$, mulsa organik, sekop, cangkul, label, timbangan, dan alat tulis. Tahap pelaksanaan yaitu inokulum diperbanyak dengan menggunakan media YEM cair sebanyak $3.600 \mathrm{ml}$ dengan kepadatan populasi bakteri sebesar $8,3 \times 10^{-7} \mathrm{cfu} /$ ml. Lahan diolah dan kemudian dilakukan pengambilan sampel untuk dianalisis kadar salinitasnya (Tabel 1.)

Setiap bedengan berukuran $2 \mathrm{~m} \times 2 \mathrm{~m}$ dan diberi label sesuai perlakuan perbedaan waktu inokulasi bakteri Rhizobium sp. dan berbagai jenis mulsa organik yang digunakan. Pupuk urea, SP36, dan $\mathrm{KCl}$ diaplikasikan sebagai pupuk dasar 
Tabel 3. Rerata Jumlah Daun Kacang Tanah (Arachis hypogaea L. var. Takar) pada Berbagai Jenis Mulsa Organik dan Perbedaan Waktu Inokulasi Bakteri Rhizobium sp.

\begin{tabular}{|c|c|c|c|c|c|}
\hline \multirow[b]{2}{*}{ Mulsa Organik } & \multicolumn{4}{|c|}{ Perbedaan Waktu Inokulasi Rhizobium sp. } & \multirow[b]{2}{*}{ Rerata } \\
\hline & $\begin{array}{c}\text { Tanpa } \\
\text { Inokulasi }\end{array}$ & $\begin{array}{c}\text { Inokulasi } \\
\text { Saat Tanam }\end{array}$ & $\begin{array}{c}\text { Inokulasi } \\
7 \mathrm{HST} \\
\end{array}$ & $\begin{array}{c}\text { Inokulasi } \\
14 \mathrm{HST}\end{array}$ & \\
\hline & \multicolumn{5}{|c|}{ 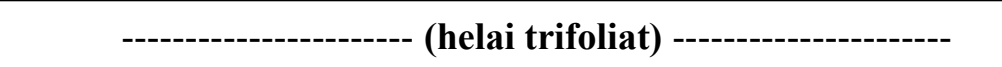 } \\
\hline Tanpa Mulsa Organik & 113,9 & 112,8 & 147 & 117 & 122,7 \\
\hline Mulsa Organik Jerami Padi & 132,9 & 162,7 & 182,3 & 150,7 & 157,6 \\
\hline Mulsa Organik Sekam Padi & 111,9 & 145 & 118,4 & 149,3 & 131,2 \\
\hline Rerata & 119,6 & 140,1 & 149,2 & 139 & \\
\hline
\end{tabular}

sesuai dengan dosis yang dianjurkan bersamaan dengan pengelolaan lahan. Aplikasi mulsa organik dilakukan setelah bedengan jadi dan dibiarkan selama 14 hari agar unsur-unsur hara dari mulsa tersebut mulai luruh. Setelah 14 hari, setiap bedengan diberi lubang tanam dengan jarak tanam $30 \mathrm{~cm} \times 30 \mathrm{~cm}$. Benih kacang tanah ditanam dengan 2 benih tiap lubang tanam. Aplikasi inokulum dilakukan sesuai perlakuan, yaitu saat tanam, 7 hari setelah tanam, dan 14 hari setelah tanam dengan ketentuan $300 \mathrm{ml}$ pada setiap bedeng berukuran $2 \mathrm{~m} \times 2 \mathrm{~m}$ (Chalim, 2010). Perawatan dilakukan setiap hari dengan melakukan penyiraman dan penyiangan gulma. Pengendalian hama dan penyakit tanaman dilakukan secara mekanik. Pembumbunan dilakukan pada 40 HST.

\section{Parameter Pengamatan}

Parameter yang diamati dalam penelitian ini adalah bobot kacang tanah per petak, tinggi tanaman, jumlah daun, bobot polong per petak, jumlah polong, jumlah biji per petak, bobot biji per petak, bobot 100 biji, dan jumlah bintil akar.

\section{HASIL DAN PEMBAHASAN}

\section{Tinggi Tanaman}

Hasil analisis ragam menunjukkan bahwa perbedaan jenis mulsa organik berpengaruh nyata $(\mathrm{P}<0,05)$ terhadap tinggi tanaman, sedangkan perbedaan waktu inokulasi bakteri Rhizobium $s p$. tidak berpengaruh nyata terhadap tinggi tanaman. Tidak adanya interaksi antara perbedaan waktu inokulasi bakteri Rhizobium sp. dan perbedaan mulsa organik. Rerata tinggi tanaman kacang tanah (Arachis hypogaea L. var. Takar) pada berbagai jenis mulsa organik dan perbedaan waktu

Tabel 4. Rerata Jumlah Polong per Petak Kacang Tanah (Arachis hypogaea L. var. Takar) pada Berbagai Jenis Mulsa Organik dan Perbedaan Waktu Inokulasi Bakteri Rhizobium sp.

\begin{tabular}{|c|c|c|c|c|c|}
\hline \multirow[b]{2}{*}{ Mulsa Organik } & \multicolumn{4}{|c|}{ Perbedaan Waktu Inokulasi Rhizobium sp. } & \multirow[b]{2}{*}{ Rerata } \\
\hline & $\begin{array}{c}\text { Tanpa } \\
\text { Inokulasi }\end{array}$ & $\begin{array}{c}\text { Inokulasi } \\
\text { Saat Tanam }\end{array}$ & $\begin{array}{c}\text { Inokulasi } \\
7 \mathrm{HST} \\
\end{array}$ & $\begin{array}{c}\text { Inokulasi } \\
14 \mathrm{HST}\end{array}$ & \\
\hline & ---------. & (n) & ouah) ----- & 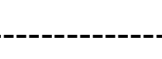 & ----- \\
\hline Tanpa Mulsa Organik & 261 & 237,3 & 228,3 & 251,7 & 244,6 \\
\hline Mulsa Organik Jerami Padi & 365,7 & 275,7 & 437,3 & 377,7 & 364,1 \\
\hline Mulsa Organik Sekam Padi & 299 & 380,3 & 256,7 & 283,3 & 304,8 \\
\hline Rerata & 308,6 & 297,8 & 307,4 & 304,2 & \\
\hline
\end{tabular}


inokulasi bakteri Rhizobium $s p$. dapat dilihat pada Tabel 2.

Hasil DMRT pada Tabel 2 menunjukkan bahwa tinggi tanaman pada perlakuan mulsa organik jerami padi menunjukkan hasil lebih tinggi secara signifikan dibandingkan dengan mulsa sekam padi dan tanpa mulsa organik. Rerata tinggi tanaman pada mulsa jerami padi sebesar $62,1 \mathrm{~cm}$, sedangkan mulsa sekam padi sebesar $50,1 \mathrm{~cm}$ dan tanpa mulsa organik sebesar 47,7 cm. Hal ini dikarenakan mulsa organik jerami padi dapat menutupi seluruh permukaan tanah, sehingga sinar matahari tidak langsung terkena tanah. Mulsa jerami padi yang menutupi seluruh permukaan tanah diduga dapat menurunkan suhu dan meningkatkan lengas tanah, sehingga tanah memiliki persediaan air untuk pertumbuhan tanaman. Hal ini sesuai dengan pendapat Harsono (2012) yang menyatakan bahwa mulsa jerami padi dapat meningkatkan lengas tanah dibandingkan dengan mulsa jenis lain. Mulsa sekam padi hanya meningkatkan tinggi tanaman pada umur tertentu karena perbedaan kelembaban. Hal ini sesuai dengan pendapat Prasetyo et al. (2014) yang menyatakan bahwa tinggi tanaman dengan perlakuan mulsa organik sekam padi meningkat ketika tanaman legum berumur 12, 24, dan 60 HST, namun pada umur 12 dan 48 HST tinggi tanaman legum dengan mulsa organik sekam padi lebih rendah dibandingkan dengan perlakuan tanpa mulsa. Mulsa organik jerami padi juga diduga dapat berfungsi sebagai amelioran untuk mengurangi kadar salinitas, sehingga tanaman dapat tumbuh dengan baik. Hal ini sesuai dengan pendapat Purwaningrahayu dan Kuntyastuti (2016) yang menyatakan bahwa penggunaan mulsa jerami padi sebagai amelioran dapat menurunkan $\mathrm{Na}^{+}, \mathrm{K}^{+}, \mathrm{Ca}^{2+}, \mathrm{Mg}^{2+}$, dan $\mathrm{Cl}^{-}$

\section{Jumlah Daun}

Hasil analisis ragam menunjukkan bahwa perbedaan jenis mulsa organik dan perbedaan waktu inokulasi bakteri Rhizobium sp. tidak berpengaruh nyata terhadap jumlah daun. Tidak adanya interaksi antara perbedaan waktu inokulasi bakteri Rhizobium $s p$. dan perbedaan mulsa organik. Rerata jumlah daun kacang tanah (Arachis hypogaea L. var. Takar) pada berbagai jenis mulsa organik dan perbedaan waktu inokulasi bakteri Rhizobium sp. dapat dilihat pada Tabel 3.

Hasil DMRT menunjukkan bahwa pemberian mulsa organik jerami padi dan sekam padi belum dapat meningkatkan jumlah daun tanaman kacang tanah. Hal ini diduga karena penelitian dilakukan ketika musim kemarau, sehingga jumlah air yang ditahan oleh mulsa tidak terlalu sedikit. Hal ini sesuai dengan pendapat Wajunie et al. (2012) yang menyatakan bahwa pemberian mulsa organik jerami padi dapat memperlambat terjadinya evaporasi, sehingga air dalam tanah dapat dimanfaatkan untuk pertumbuhan kacang tanah, namun akan terganggu jika jumlah air terlalu sedikit. Belum meningkatnya jumlah daun tanaman kacang tanah diduga karena aktivitas dari bakteri Rhizobium $s p$.

Tabel 5. Rerata Bobot Polong per Petak Kacang Tanah (Arachis hypogaea L. var. Takar) pada Berbagai Jenis Mulsa Organik dan Perbedaan Waktu Inokulasi Bakteri Rhizobium sp.

\begin{tabular}{cccccc}
\hline \multirow{2}{*}{ Mulsa Organik } & \multicolumn{4}{c}{ Perbedaan Waktu Inokulasi Rhizobium sp. } & \multirow{2}{*}{ Rerata } \\
\cline { 2 - 5 } & $\begin{array}{c}\text { Tanpa } \\
\text { Inokulasi }\end{array}$ & $\begin{array}{c}\text { Inokulasi } \\
\text { Saat Tanam }\end{array}$ & $\begin{array}{c}\text { Inokulasi } \\
\text { 7 HST }\end{array}$ & $\begin{array}{c}\text { Inokulasi } \\
\text { 14 HST }\end{array}$ & \\
\hline Tanpa Mulsa Organik & 517,7 & 7,489 & 447,3 & 357,7 & 453,3 \\
Mulsa Organik Jerami Padi & 692,3 & 483 & 7,789 & 702,7 & 666,7 \\
Mulsa Organik Sekam Padi & 531,7 & 3,666 & 3,470 & 495,3 & 540,7 \\
\hline Rerata & 580,6 & 3,546 & 1,569 & 518,6 & \\
\hline
\end{tabular}


Tabel 6. Rerata Bobot 100 Biji Kacang Tanah (Arachis hypogaea L. var. Takar) pada Berbagai Jenis Mulsa Organik dan Perbedaan Waktu Inokulasi Bakteri Rhizobium sp.

\begin{tabular}{cccccc}
\hline \multirow{2}{*}{ Mulsa Organik } & \multicolumn{4}{c}{ Perbedaan Waktu Inokulasi Rhizobium sp. } & \multirow{2}{*}{ Rerata } \\
\cline { 2 - 5 } & $\begin{array}{c}\text { Tanpa } \\
\text { Inokulasi }\end{array}$ & $\begin{array}{c}\text { Inokulasi } \\
\text { Saat Tanam }\end{array}$ & $\begin{array}{c}\text { Inokulasi } \\
\text { 7 HST }\end{array}$ & $\begin{array}{c}\text { Inokulasi } \\
\text { 14 HST }\end{array}$ & \\
\hline Tanpa Mulsa Organik & 29,3 & 31,9 & 33,8 & 32,7 & 31,9 \\
Mulsa Organik Jerami Padi & 31,4 & 30 & 34,6 & 33,6 & 32,4 \\
Mulsa Organik Sekam Padi & 33,9 & 25,6 & 33,7 & 36,6 & 32,5 \\
\hline Rerata & 31,5 & 29,2 & 34 & 34,3 & \\
\hline
\end{tabular}

di lahan salin kurang optimal, sehingga bakteri Rhizobium sp. tidak dapat bersimbiosis dengan akar tanaman kacang tanah dan memfiksasi nitrogen untuk pertumbuhan vegetatif tanaman. Hal ini sesuai dengan pendapat Fuskhah et al. (2014) yang menyatakan bahwa cekaman salinitas akan menghambat pertumbuhan dan aktivitas bakteri Rhizobium sp. dalam memfiksasi nitrogen bebas.

\section{Jumlah Polong per Petak}

Hasil analisis ragam menunjukkan bahwa perbedaan jenis mulsa organik dan perbedaan waktu inokulasi bakteri Rhizobium $s p$. belum berpengaruh nyata terhadap jumlah polong per petak. Tidak adanya interaksi antara perbedaan waktu inokulasi bakteri Rhizobium sp. dan perbedaan mulsa organik. Rerata jumlah polong per petak kacang tanah (Arachis hypogaea L. var. Takar) pada berbagai jenis mulsa organik dan perbedaan waktu inokulasi bakteri Rhizobium $s p$. dapat dilihat pada Tabel 4.

Berdasarkan Tabel 4, pemberian berbagai mulsa organik dan perbedaan waktu inokulasi bakteri Rhizobium sp. belum mampu untuk meningkatkan jumlah polong per petak. Hal ini diduga karena pemberian mulsa organik belum mampu menurunkan cekaman salinitas sehingga mengganggu pertumbuhan tanaman. Klorofil daun tanaman yang terkena cekaman salinitas akan rusak dan berdampak pada proses fotosintesis dan pembentukan asimilat yang berpengaruh terhadap pembentukan polong dan biji. Hal ini sesuai dengan pendapat Taufiq dan Purwaningrahayu (2013) yang menyatakan bahwa pertumbuhan vegetatif tanaman akan menurun dan klorofil daun rusak, yang akan berdampak pada pembentukan polong dan biji. Pemberian inokulasi Rhizobium $s p$. belum mampu meningkatkan jumlah polong per petak dikarenakan inokulum bakteri Rhizobium sp. yang digunakan untuk penelitian merupakan inokulum introduksi. Sehingga inokulum bakteri Rhizobium $s p$. berkompetisi dengan Rhizobium sp. native dan berdampak pada simbiosis dengan akar tanaman tersebut. Hal ini sesuai dengan pendapat Maryani dan Hapsoh (2011) yang menyatakan bahwa akan terjadi persaingan antara Rhizobium sp. introduksi dengan native ketika diberikan perlakuan inokulasi dan akan mempengaruhi produksi polong tanaman.

\section{Bobot Polong per Petak}

Hasil analisis ragam menunjukkan bahwa perbedaan jenis mulsa organik dan perbedaan waktu inokulasi bakteri Rhizobium $s p$. tidak berpengaruh nyata terhadap bobot polong per petak. Tidak adanya interaksi antara perbedaan waktu inokulasi bakteri Rhizobium sp. dan perbedaan mulsa organik. Rerata bobot polong per petak kacang tanah (Arachis hypogaea L. var. Takar) pada berbagai jenis mulsa organik dan perbedaan waktu inokulasi bakteri Rhizobium $s p$. dapat dilihat pada Tabel 5.

Berdasarkan Tabel 5, pemberian berbagai mulsa organik dan perbedaan waktu inokulasi bakteri Rhizobium sp. belum mampu untuk meningkatkan bobot polong per petak. Belum meningkatnya bobot polong per tanaman, diduga karena adanya cekaman salinitas yang tinggi. 
Tabel 7. Rerata Jumlah Biji per Petak Kacang Tanah (Arachis hypogaea L. var. Takar) pada Berbagai Jenis Mulsa Organik dan Perbedaan Waktu Inokulasi Bakteri Rhizobium sp.

\begin{tabular}{cccccc}
\hline \multirow{2}{*}{ Mulsa Organik } & \multicolumn{3}{c}{ Perbedaan Waktu Inokulasi Rhizobium sp. } & \multirow{2}{*}{ Rerata } \\
\cline { 2 - 5 } & $\begin{array}{c}\text { Tanpa } \\
\text { Inokulasi }\end{array}$ & $\begin{array}{c}\text { Inokulasi } \\
\text { Saat Tanam }\end{array}$ & $\begin{array}{c}\text { Inokulasi } \\
\text { 7 HST }\end{array}$ & $\begin{array}{c}\text { Inokulasi } \\
\text { 14 HST }\end{array}$ & \\
\hline Tanpa Mulsa Organik & 311 & 254 & 240,3 & 542,7 & 337 \\
Mulsa Organik Jerami Padi & 395,7 & 399,7 & 375,3 & 417,3 & 397 \\
Mulsa Organik Sekam Padi & 192 & 325 & 186,7 & 341,3 & 261,3 \\
\hline Rerata & 299,6 & 326,2 & 267,4 & 433,8 & \\
\hline
\end{tabular}

Cekaman salinitas lahan penelitian hingga $6,4 \mathrm{dS} /$ $\mathrm{m}$ akan menghambat pembentukan polong dan berpengaruh terhadap bobot polong. Cekaman salinitas akan mengganggu proses distribusi fotosintat pada stadia pembentukan polong. Hal ini sesuai dengan pendapat Taufiq et al. (2015) yang menyatakan bahwa pada stadia generatif sangat sensitif terhadap cekaman salinitas, sehingga cekaman salinitas dapat mengganggu distribusi asimilat untuk pengisian polong.

Pemilihan varietas juga mempengaruhi terhadap pembentukan polong. Varietas Takar merupakan salah satu varietas unggul yang dilepas oleh Balitkabi yang tahan terhadap cekaman salin pada tingkat tertentu. Varietas Takar dalam penelitian ini tidak terserang nekrosis yang diakibatkan oleh cekaman salin, namun masih mengalami penurunan hasil. Penurunan hasil pada penelitian ini sebesar 34,2\% - 62,735\%. Mungala et al. (2009) menyatakan bahwa tanaman kacang tanah yang ditanam pada tingkat salinitas $2 \mathrm{dS} / \mathrm{m}$ - $10 \mathrm{dS} / \mathrm{m}$ mengalami penurunan hasil sebanyak $100 \%$, namun dapat diatasi dengan pemberian amelioran.

\section{Bobot 100 Biji}

Hasil analisis ragam menunjukkan bahwa perbedaan jenis mulsa organik dan perbedaan waktu inokulasi bakteri Rhizobium sp. tidak berpengaruh nyata terhadap bobot 100 biji. Tidak adanya interaksi antara perbedaan waktu inokulasi bakteri Rhizobium sp. dan perbedaan mulsa organik. Rerata bobot 100 biji kacang tanah (Arachis hypogaea L. var. Takar) pada berbagai jenis mulsa organik dan perbedaan waktu inokulasi bakteri Rhizobium sp. dapat dilihat pada

Tabel 8. Rerata jumlah bintil akar Kacang Tanah (Arachis hypogaea L. var. Takar) pada berbagai jenis mulsa organik dan perbedaan waktu inokulasi bakteri Rhizobium sp.

\begin{tabular}{cccccc}
\hline \multirow{2}{*}{ Mulsa Organik } & \multicolumn{4}{c}{ Perbedaan Waktu Inokulasi Rhizobium $\mathrm{sp.}$} & \multirow{2}{*}{ Rerata } \\
\cline { 2 - 5 } & $\begin{array}{c}\text { Tanpa } \\
\text { Inokulasi }\end{array}$ & $\begin{array}{c}\text { Inokulasi } \\
\text { Saat Tanam }\end{array}$ & $\begin{array}{c}\text { Inokulasi } \\
\text { 7 HST }\end{array}$ & $\begin{array}{c}\text { Inokulasi } \\
\text { 14 HST }\end{array}$ & \\
\hline Tanpa Mulsa Organik & 0,04 & 0,83 & 0,88 & 0,58 & 0,58 \\
Mulsa Organik Jerami Padi & 0,79 & 2,42 & 1,21 & 0,88 & 1,32 \\
Mulsa Organik Sekam Padi & 0,71 & 2,32 & 1,63 & 0,88 & 1,38 \\
\hline Rerata & $0,51^{\mathrm{b}}$ & $1,86^{\mathrm{a}}$ & $1,24^{\mathrm{ab}}$ & $0,78^{\mathrm{b}}$ & \\
\hline
\end{tabular}

* Superskrip yang berbeda pada baris rerata menunjukkan perbedaan yang nyata $(\mathrm{p}<0,05)$. 
Tabel 6 .

Pemberian berbagai mulsa organik dan perbedaan waktu pemberian inokulasi bakteri Rhizobium $s p$. belum mampu meningkatkan bobot 100 biji. Hal ini diduga karena tidak adanya pemupukan lanjutan dengan pupuk anorganik. Sehingga tidak tersedianya nutrisi yang cukup untuk pengisian polong dan biji. Tidak dilakukannya pemupukan lanjutan bertujuan untuk mengamati pengaruh dari inokulasi Rhizobium sp., namun tidak terjadi peningkatan dalam bobot 100 biji. Hal ini sesuai dengan pendapat Astiko (2018) yang menyatakan bahwa pemberian inokulum tanpa penambahan pupuk anorganik tidak berpengaruh nyata terhadap bobot 1.000 biji tanaman kedelai.

Hal lain yang diduga menghambat pembentukan polong adalah tidak sempurnanya perkembangan ginofor. Ginofor pada penelitian ini tidak dapat berkembang dengan sempurna untuk membentuk polong dan biji karena tanah penelitian yang tidak gembur meskipun telah dilakukan pembumbunan. Kondisi tanah yang tidak gembur akan membuat ginofor sulit untuk menembus tanah. Hal ini sesuai dengan pendapat Sembiring et al. (2014) yang menyatakan bahwa tanah yang gembur akan memudahkan ginofor untuk menembus tanah dan dapat dengan mudah berkembang untuk membentuk polong dan biji.

\section{Jumlah Biji per Petak}

Hasil analisis ragam menunjukkan bahwa perbedaan jenis mulsa organik dan perbedaan waktu inokulasi bakteri Rhizobium sp. tidak berpengaruh nyata terhadap jumlah biji per petak. Tidak adanya interaksi antara perbedaan waktu inokulasi bakteri Rhizobium sp. dan perbedaan mulsa organik. Rerata jumlah biji per petak kacang tanah (Arachis hypogaea L. var. Takar) pada berbagai jenis mulsa organik dan perbedaan waktu inokulasi bakteri Rhizobium sp. dapat dilihat pada Tabel 7.

Pemberian berbagai mulsa organik dan perbedaan waktu pemberian inokulasi bakteri Rhizobium sp. belum mampu meningkatkan jumlah biji per petak. Hal ini diduga karena cekaman salinitas pada lahan penelitian dapat menurunkan proses pembentukan biji. Kacang tanah dapat menghasilkan biji dengan baik dengan ambang batas salinitas tertentu. Lahan penelitian yang digunakan memiliki tingkat salinitas cukup tinggi sebesar $6,4 \mathrm{dS} / \mathrm{m}$, sehingga akan mengganggu pembentukan biji. Hal ini sesuai dengan pendapat Taufiq et al. (2015) yang menyatakan bahwa ambang batas salinitas kacang tanah untuk dapat membentuk polong antara 5,43 $-6,45 \mathrm{dS} / \mathrm{m}$. Pemberian berbagai mulsa organik dan perbedaan waktu pemberian inokulasi bakteri Rhizobium sp. belum mampu meningkatkan jumlah biji per petak juga diduga berhubungan dengan pertumbuhan vegetatif tanaman. Jumlah daun pada penelitian kali ini (Tabel 3) juga terhambat oleh cekaman salinitas. Cekaman salinitas akan menghambat pertumbuhan vegetatif tanaman dan akan berpengaruh terhadap pembentukan biji. Hal ini sesuai dengan pendapat Taufiq dan Purwaningrahayu (2013) yang menyatakan bahwa cekaman salinitas akan menghambat pertumbuhan tanaman legum yang ditunjukkan dengan berkurangnya jumlah daun dan tinggi tanaman serta merusak klorofil daun sehingga berdampak pada proses pembentukan polong dan biji.

\section{Jumlah Bintil Akar}

Hasil analisis ragam menunjukkan bahwa perbedaan jenis mulsa organik tidak berpengaruh nyata terhadap jumlah bintil akar, sedangkan perbedaan waktu inokulasi bakteri Rhizobium $s p$. berpengaruh nyata $(\mathrm{P}<0,05)$ terhadap jumlah bintil akar. Tidak adanya interaksi antara perbedaan waktu inokulasi bakteri Rhizobium sp. dan perbedaan mulsa organik. Rerata jumlah bintil akar dari 15 sampel tanaman kacang tanah (Arachis hypogaea L. var. Takar) pada berbagai jenis mulsa organik dan perbedaan waktu inokulasi bakteri Rhizobium sp. dapat dilihat pada Tabel 8.

Hasil DMRT menunjukkan bahwa inokulasi saat tanam menghasilkan jumlah bintil akar tertinggi dibandingkan tanpa inokulasi dan inokulasi 14 HST, namun tidak berbeda pada 7 HST. Proses pemberian inokulasi saat tanam dilakukan dengan cara merendam benih kacang tanah dalam inokulum selama 5 menit sesaat sebelum ditanam. Peningkatan jumlah bintil dalam perlakuan inokulasi saat tanam memiliki nilai tertinggi dikarenakan banyaknya bakteri Rhizobium sp. yang dapat bersimbiosis dengan tanaman kacang tanah dan membentuk bintil akar. 
Hal ini sesuai dengan pendapat Purwaningsih (2015) yang menyatakan bahwa pemberian inokulum pada saat tanam akan meningkatkan jumlah bintil secara nyata pada tanaman kedelai. Tanah pada penelitian ini memiliki kadar nitrogen sebesar $0,66 \%$ dan tidak mendapatkan pemupukan lanjutan, hanya mendapatkan urea pada awal tanam. Semakin sedikit unsur N yang ada dalam tanah, membuat bakteri Rhizobium sp. dapat maksimal menambat unsur $\mathrm{N}$ bebas. Hal ini sesuai dengan pendapat Mulyadi (2012) yang menyatakan bahwa pemberian sedikit starter pupuk $\mathrm{N}$ pada fase vegetatif, akan menyebabkan bakteri Rhizobium sp. semakin maksimal dalam membentuk bintil.

\section{KESIMPULAN}

Berdasarkan penelitian yang telah dilakukan, dapat disimpulkan bahwa pemberian mulsa organik jerami padi mampu meningkatkan tinggi tanaman dan pemberian inokulasi bakteri Rhizobium sp. saat tanam mampu meningkatkan jumlah bintil akar kacang tanah. Pemberian berbagai jenis mulsa organik dan perbedaan waktu inokulasi bakteri Rhizobium sp. belum mampu meningkatkan jumlah daun, jumlah polong per petak, bobot polong per petak, jumlah biji per petak, dan bobot 100 biji kacang tanah pada lahan dengan tingkat salinitas $6,4 \mathrm{dS} / \mathrm{m}$.

\section{DAFTAR PUSTAKA}

Aminah, S., Rosmayati, dan L. A. M. Siregar. 2013. Seleksi galur kedelai (Glycine max (L.) Merril) generasi F3 pada tanah salin. J. Online Agroekoteknologi, 1 (3) : 637 645.

Astiko, W. 2018. Pengaruh paket pemupukan terhadap pertumbuhan dan hasil tanaman kedelai di lahan kering. J. Crop Agro, 2 (2) : $115-122$.

Badan Pusat Statistik. 2016. Statistik Luas Panen dan Produksi Tanaman Sayuran dan Buahbuahan Semusim Menurut Kabupaten/Kota di Jawa Tengah, 2015 - 2016. Available at

https://jateng.bps.go.id/statictable/2017 /11/02/1664/luas-panen-dan-produksitanaman-sayuran-dan-buah-buahansemusim-menurut-kabupaten-kota-dijawa-tengah-2015---2016.html. Diakses pada 28 April 2019 pukul 20.09.

Chalim, A. 2010. Pengaruh aplikasi rhizobium dan cendawan mikoriza arbuskula (cma) terhadap pertumbuhan semai Acasia crassicarpa A. cunn. Ex benth. Pada medium tanah terdegradasi. J. Urban and Environmental Technologies, 5 (4) : 139 144.

Fuskhah, E., R. D. Soetrisno, S. Anwar, dan F. Kusmiyati. 2014. Uji asosiasi bakteri rhizobium terseleksi dengan leguminosa pakan dalam kondisi tercekam salin. J. Agripet, 14 (1) : $65-70$.

Gresinta, E. 2015. Pengaruh pemberian monosodium glutamat (MSG) terhadap pertumbuhan dan produksi kacang tanah (Arachis hypogea L.). J. Faktor Exacta, 8 (3) : $208-219$.

Hamdani, J. S. 2009. Pengaruh jenis mulsa terhadap pertumbuhan dan hasil tiga kultivar kentang (Solanum tuberosum L.) yang ditanam di dataran medium. J. Agron. Indonesia, 37 (1) : $14-20$.

Harsono, P. 2012. Mulsa organik: pengaruhnya terhadap lingkungan mikro, sifat kimia tanah dan keragaan cabai merah di tanah vertisol sukoharjo pada musim kemarau. J. Hort. Indonesia, 3 (1) : $35-41$.

Kasno, A. dan D. Harnowo. 2014. Karakteristik varietas unggul kacang tanah dan adopsinya oleh petani. J. Iptek Tanaman Pangan, 9 (1) : $13-23$.

Laksono, R. A. 2016. Pertumbuhan dan hasil tanaman kubis bunga (Brassica oleracea $\mathrm{L}$. var. botrytis subvar. cauliflora dc.) kultivar orient $\mathrm{fl}$ akibat jenis mulsa dan dosis bokashi. J. Agrotek Indonesia, 1 (2) : 100 121. 
Lubis, P. A., S. Y. Tyasmoro, dan Sudiarso. 2017. Pengaruh jenis dan ketebalan mulsa dalam mempertahankan kandungan air tanah dan dampaknya terhadap tanaman kedelai (Glycine $\max$ (L.) di lahan kering. J. Produksi Tanaman, 5 (5) : 791 - 798.

Mulyadi, A. 2012. Pengaruh pemberian legin, pupuk NPK (15:15:15) dan urea pada tanah gambut terhadap kandungan $\mathrm{N}, \mathrm{P}$, total pupuk dan bintil akar kedelai (Glycine max (L.) Merr.). J. Kaunia, 8 (1) 21 - 29.

Mungala, A. J., T. Radhakrishnan, and J. R. D. Junagadh. 2009. In vitro screening of 123 indian peanut cultivars for sodium chloride induced salinity tolerance. J. Of Agriculture Science, 4 (5) : $574-582$.

Ni'am, A. M. dan S. H. Bintari. 2017. Pengaruh pemberian inokulan legin dan mulsa terhadap jumlah bakteri bintil akar dan pertumbuhan tanaman kedelai varietas grobogan. J. MIPA, 40 (2) : $80-86$.

Prasetyo R. A., A. Nugroho, dan J. Moenandir. 2014. Pengaruh sistem olah tanah dan berbagai mulsa organik pada pertumbuhan dan hasil tanaman kedelai (Glycine max (L.) Merr.) var. Grobogan. J. Produksi Tanaman, $1(6): 486-495$.

Purwaningrahayu, R. D. dan H. Kuntyastuti. 2016. Efektivtias amelioran dan toleransi genotip kedelai terhadap salinitas pada tanah salin. Prosiding Seminar Hasil Penelitian Tanaman Aneka Kacang dan Umbi.
Purwaningsih, S. 2015. Pengaruh inokulasi rhizobium terhadap pertumbuhan tanaman kedelai (Glycine max L.) varietas wilis di rumah kaca. J. Berita Biologi, 14 (1) : 69 76.

Sembiring, M., R. Sipayung, dan F. E. Sitepu. 2013. Pertumbuhan dan produksi kacang tanah dengan pemberian kompos tandan kosong kelapa sawit paada frekuensi pertumbuhan yang berbeda. J. Agroekoteknologi, 2 (2) : $698-606$.

Sughening, W., Tohari, dan D. Shiddieq. 2012. Pengaruh mulsa organik terhadap Respon varietas unggul kacang tanah terhadap pertumbuhan dan hasil tiga varietas kacang hijau (Vigna radiata L. Wilczek) di lahan pasir pantai bugel, kulon progo. J. Vefetalika, 1 (2) : $54-66$.

Taufiq, A. dan D. Purwaningrahayu. 2013. Tanggap varietas kacang hijau terhadap cekaman salinitas. J. Penelitian Pertanian Tanaman Pangan, 32 (3) : 159 - 170.

Taufiq, A., A. Kristiono, dan D. Harnowo. 2015. cekaman salinitas. J. Penelitian Pertanian Tanaman Pangan, 34 (2) : 153 - 163.

Wahjunie, E. D., N. Sinukaban, dan B. S. D. Damanik. 2017. Perbaikan kualitas fisik tanah menggunakan mulsa jerami padi dan pengaruhnya terhadap produksi kacang tanah. J. Tanah Lingkungan, 14 (1) : $7-13$. 